\title{
Léon Brunschvicg, De la connaissance de soi*
}

Der Verf. versucht in diesen Vorlesungen eine Wesensdeutung des Menschen zu geben, eine Anthropologie, wie man heute sagen würde. Nachdem er früher die historische Entwicklung der Philosophie als fortschreitende Eroberung und Vertiefung der geistigen Innerlichkeit des Menschen dargestellt hat (Le progrès de la conscience dans la philosophie occidentale, Paris 1927), versucht er in dem vorliegenden Werk systematisch das eigentliche Selbst des Menschen aus allen jenen Seinsbereichen herauszulösen, die man zu seiner Erklärung herangezogen hat. Von vornherein abgelehnt wird eine biologische Fundierung menschlichen Daseins (wobei der Verf. nur einen ziemlich unklar und allgemein gefaßten Vitalismus im Auge hat, ohne daß ihm die konkreten Forschungen zu seinem Gegenstand bekannt zu sein scheinen). So wird die weitere Suche nach den Sinnwurzeln menschlicher Weltorientierung von selbst auf die historische Wirklichkeit verwiesen. B. glaubt jedoch von allen Aspekten historisch-gesellschaftlicher Wirklichkeit zeigen zu können, daß sie durch Tradition und Herkommen dem Menschen sein Wesen verhüllen und nicht zu sich selbst kommen lassen. Dabei fällt uns auf, wie das ganze Werk von der eigentümlichen Paradoxie durchzogen wird, daß der Verf. die Geistperson des Menschen in der auf sich selbst gestellten Intimität ihrer Innerlichkeit zu fassen sucht und dennoch in seiner Argumentation niemals über das recht mittelmäßige Niveau einer schulmäßigen rationalen Psychologie hinauskommt, wie Tradition und Herkommen sie gebildet haben.

* Léon Brunschvicg, De la connaissance de soi. XI, 196 Seiten. Pr. 25 frcs. Felix Alcan, Paris 1931. 